Mehmood Qureshi

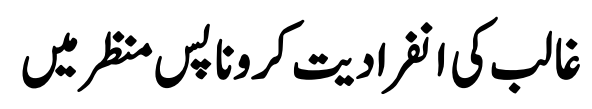

Agra U.P, India

\title{
Ghalib's Uniqueness in the Background of Corona
}

India has a special place in the historic city of Agra. Literature is remembered as Akbar Abad. The list of Urdu poets from Dabstan Akbar Abad is long enough. Mir Taqi Mir king of Ghazal, born in Agra. Not only literature, but the city of Agra has its special identity in various fields. People from different states come here.

Key Words: Special, Historic, Agra, Literature, Vrdu Poets, Identity.

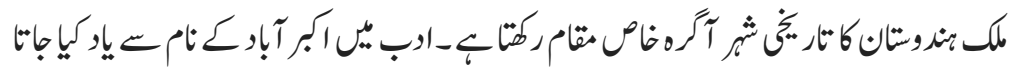

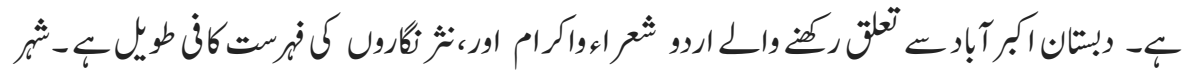

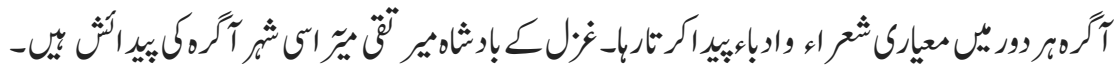

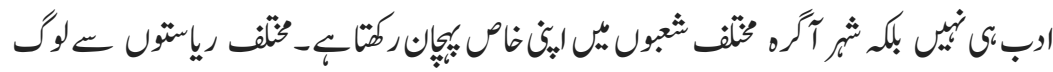

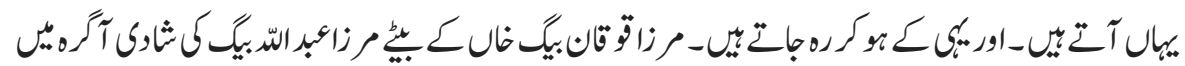

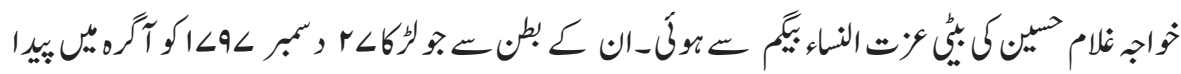

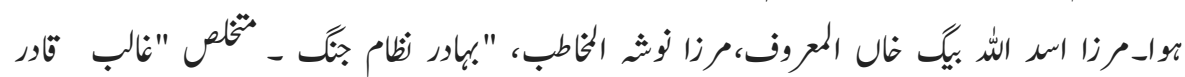

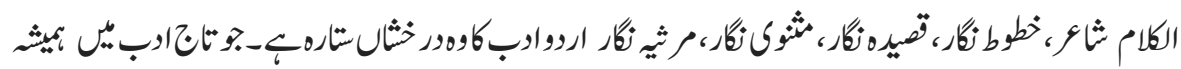

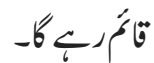

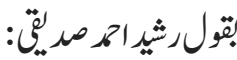

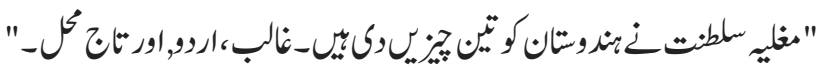

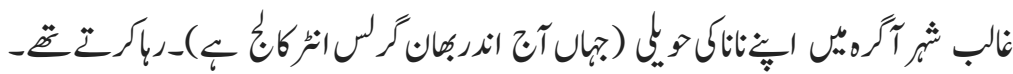




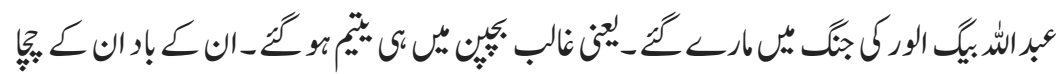

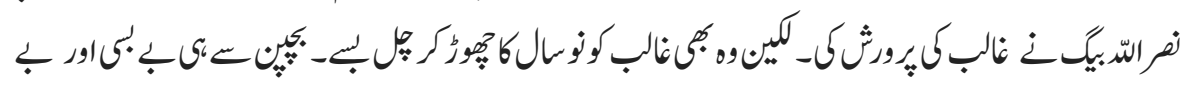

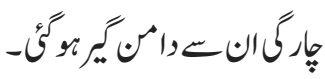

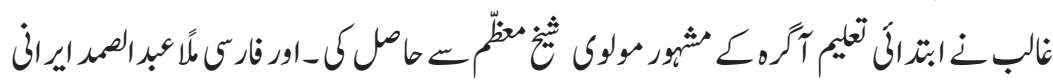

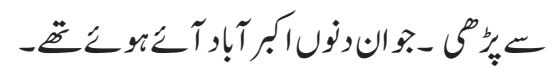

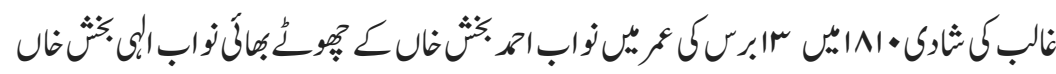

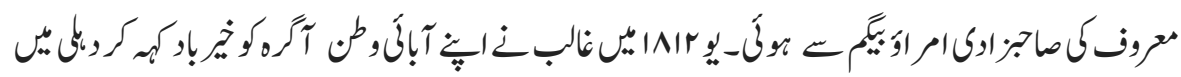

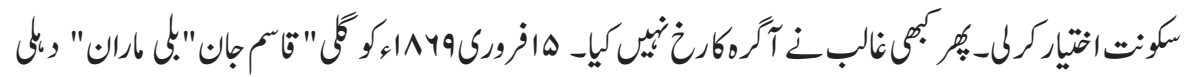

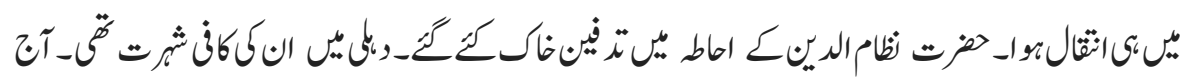

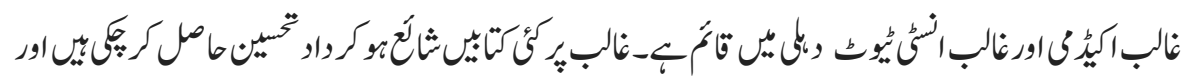

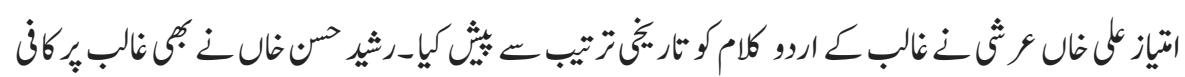

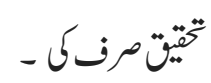

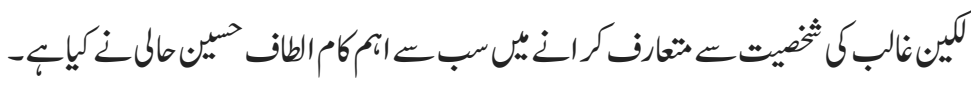

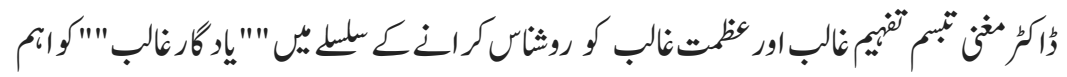

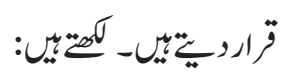

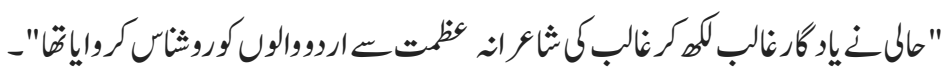

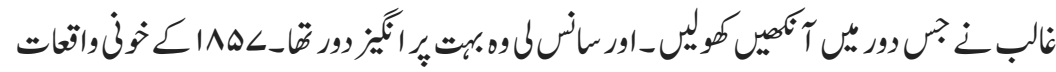

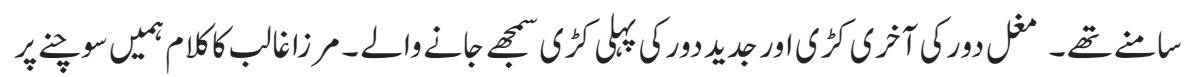

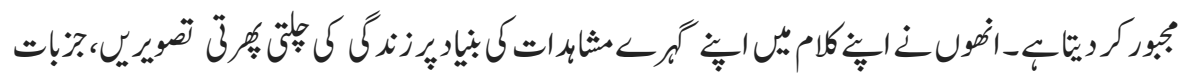

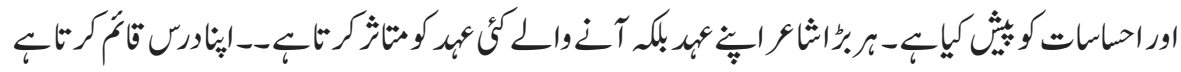

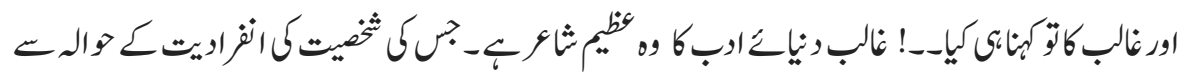

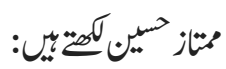




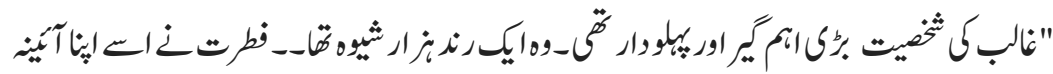

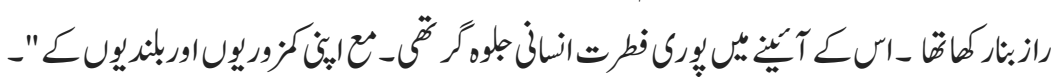

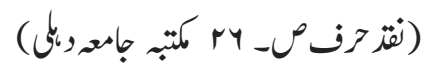

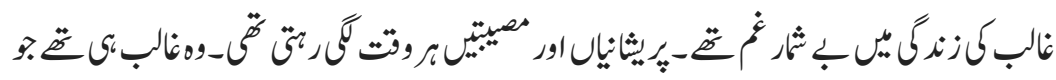

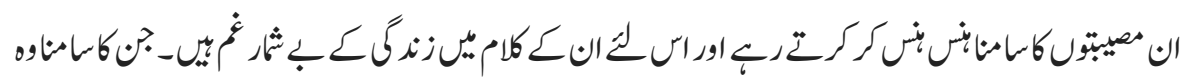

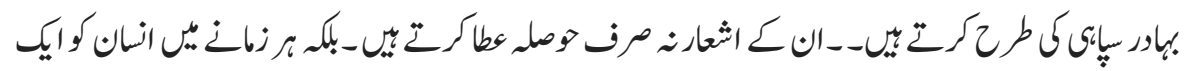

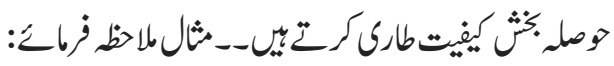

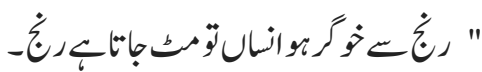

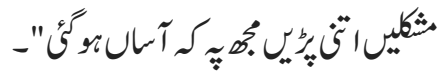

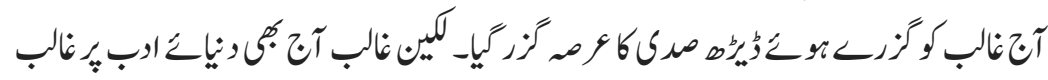

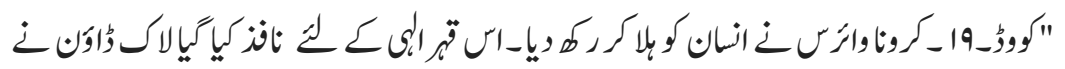

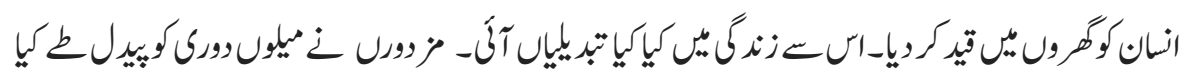

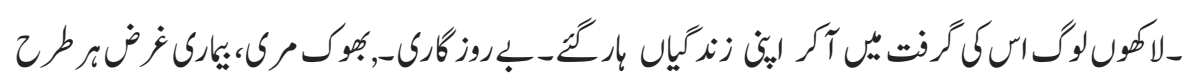

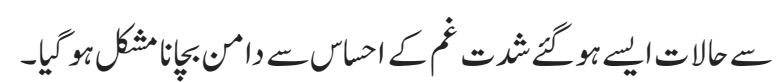

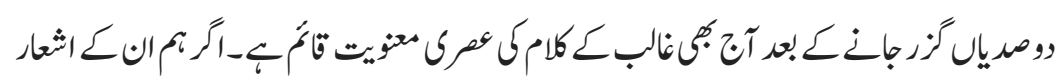

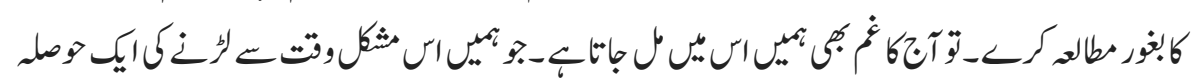

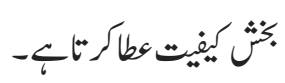

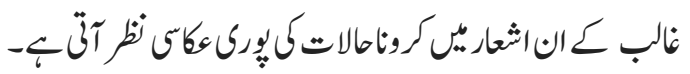

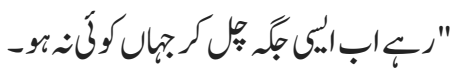

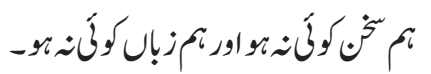

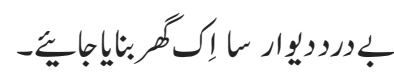

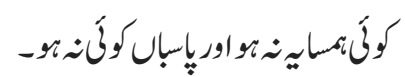


ISSN (Print): 2709-9636 | ISSN(Online) : 2709-9644 | ISSN-L : 2709-9636

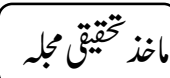

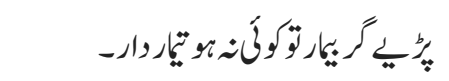

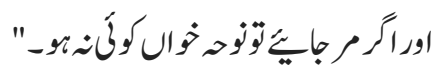

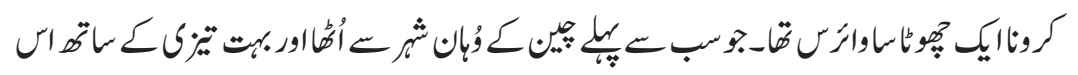

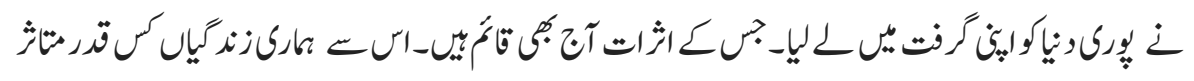

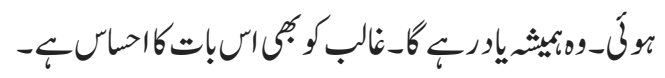

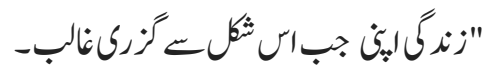

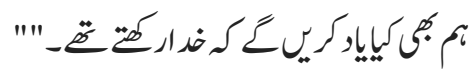

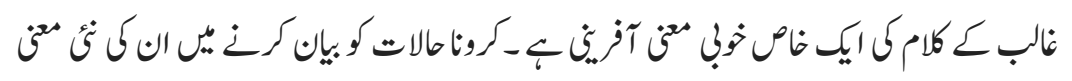

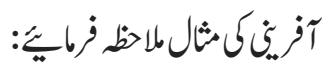

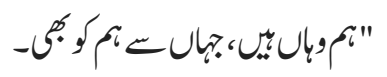

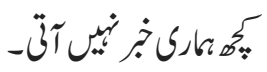

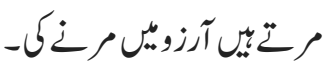

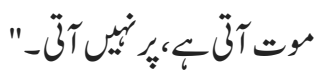

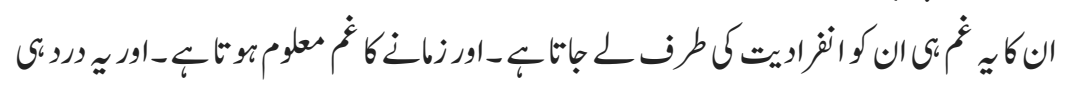

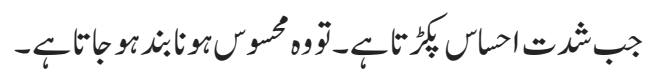

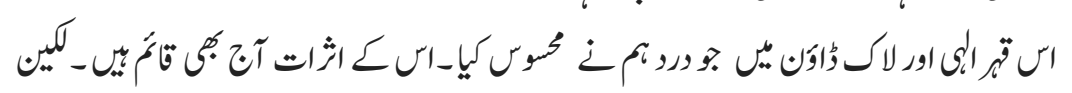

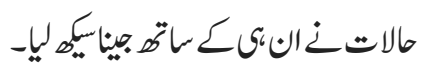

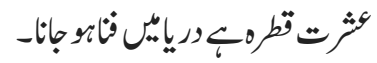

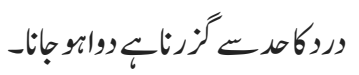

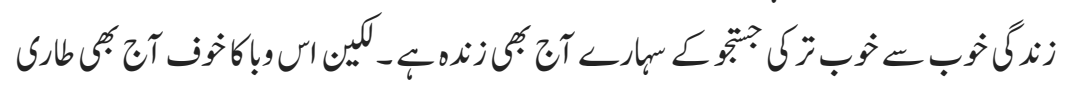

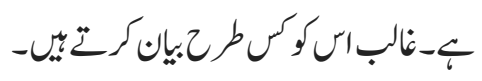

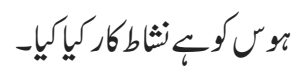

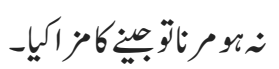

ir 


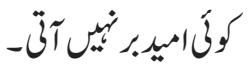

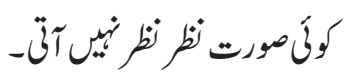

$$
\begin{aligned}
& \text { موت كايكبون ميّنب }
\end{aligned}
$$

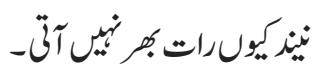

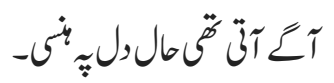

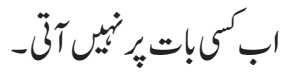

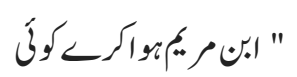

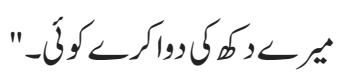

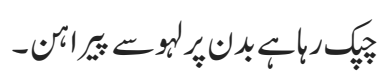

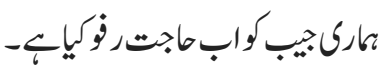

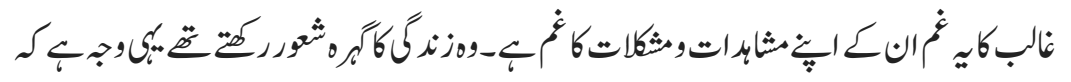

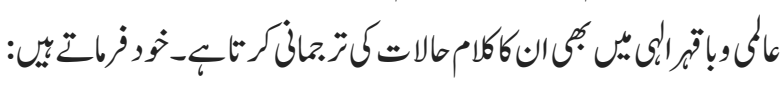

$$
\begin{aligned}
& \text {, }
\end{aligned}
$$

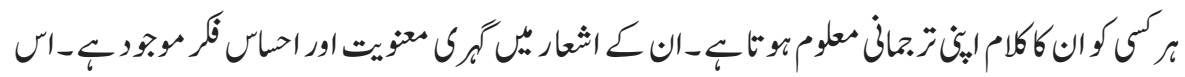

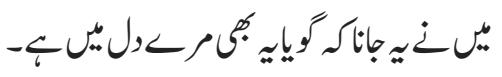

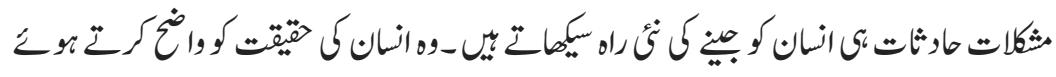

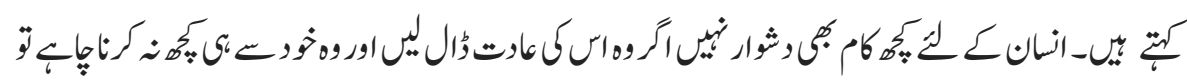
اوربات

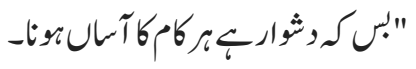

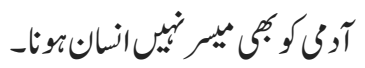

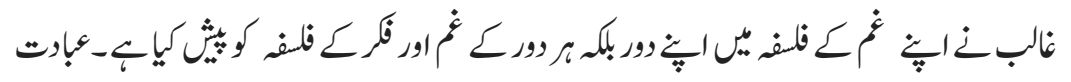

بريوكلكئين. 


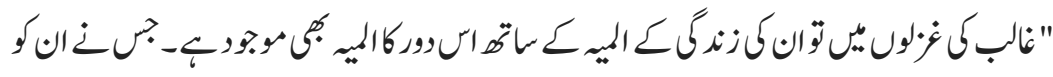

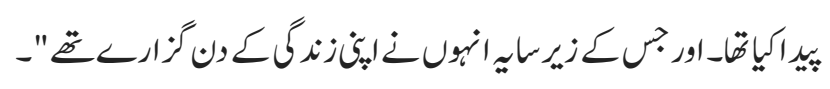

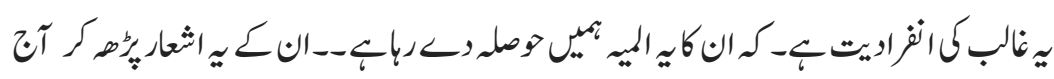

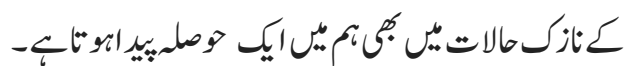

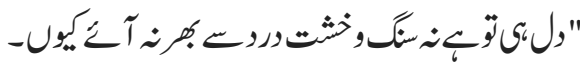

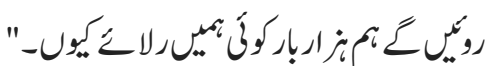

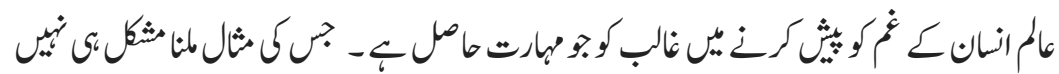

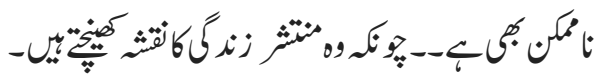

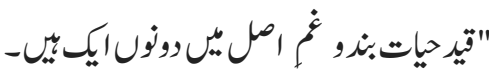

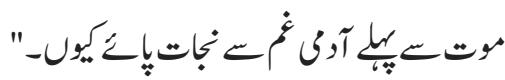

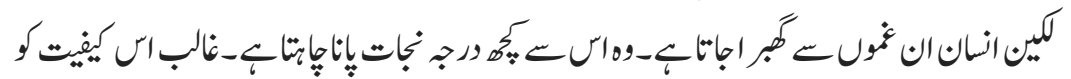

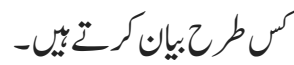

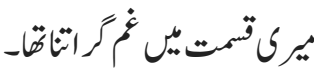

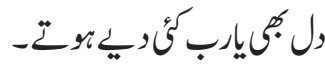

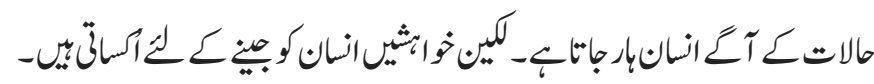

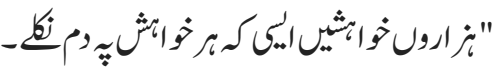

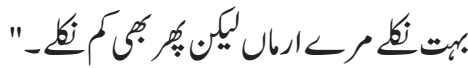

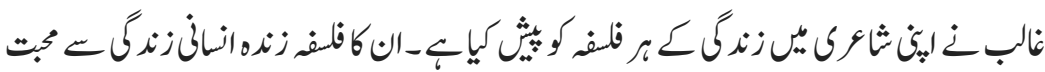

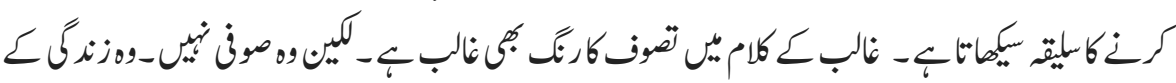

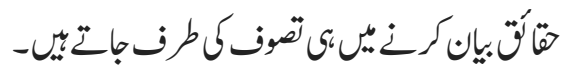

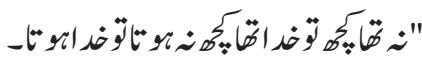

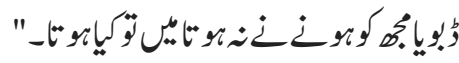

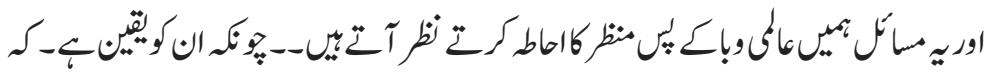




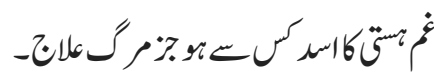

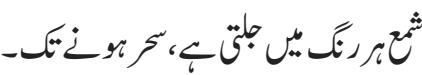

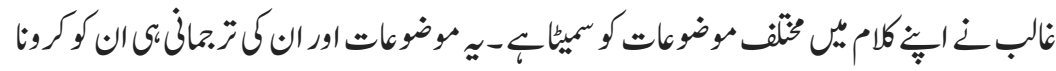

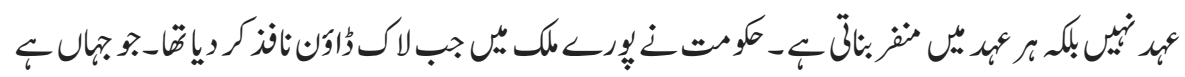

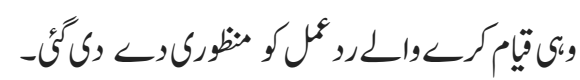

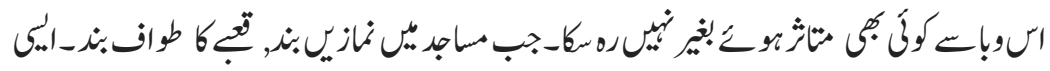

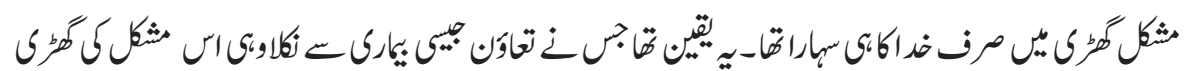

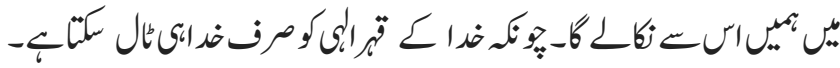

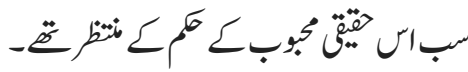

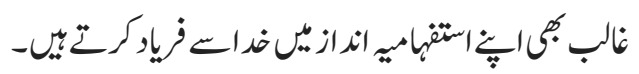

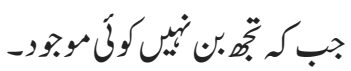

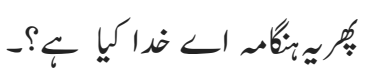

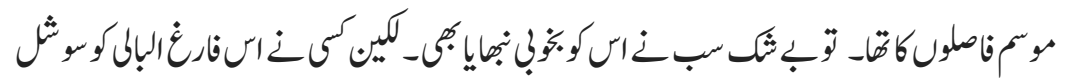

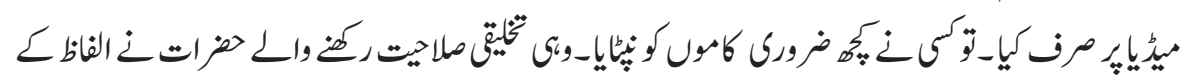

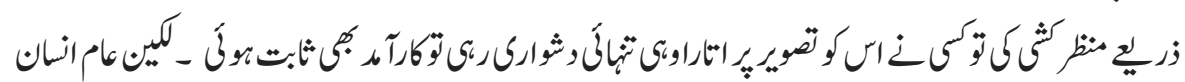

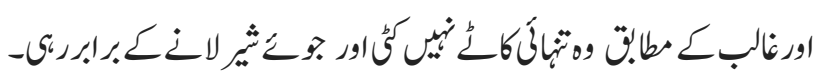

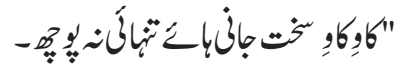

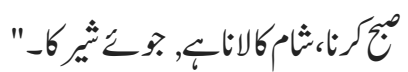

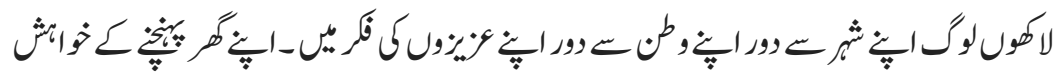

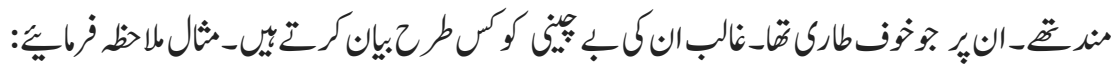

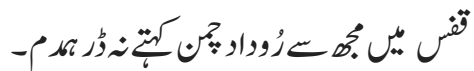

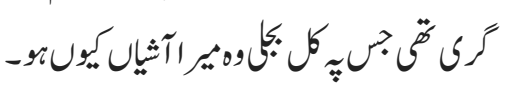




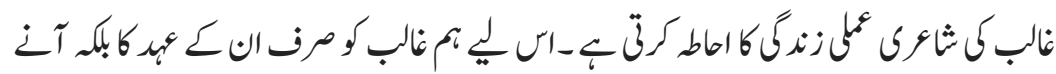

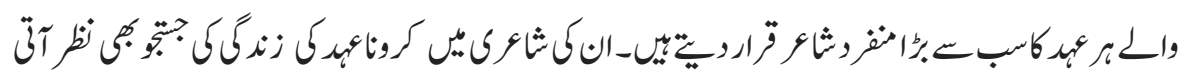

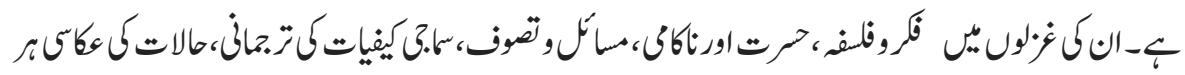

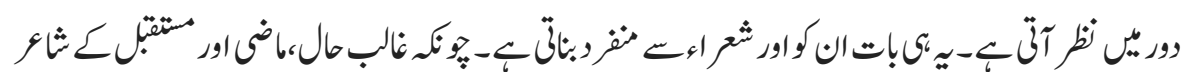

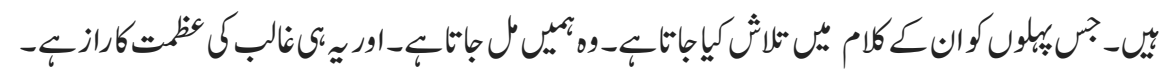

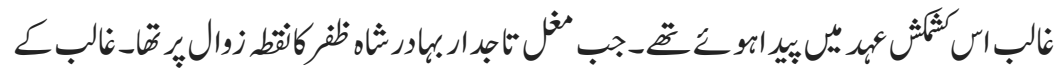

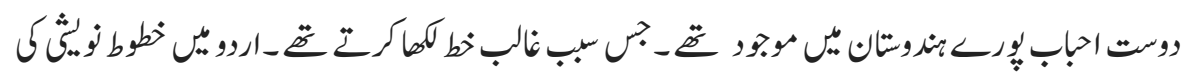

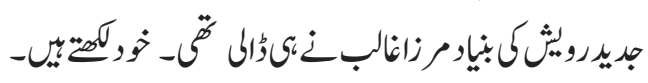

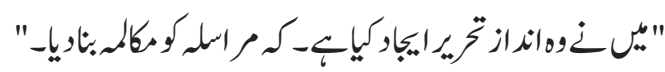

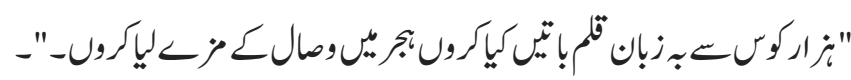

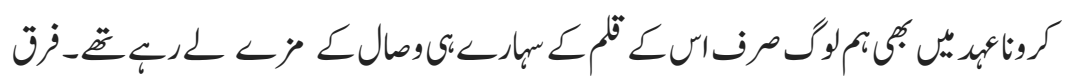

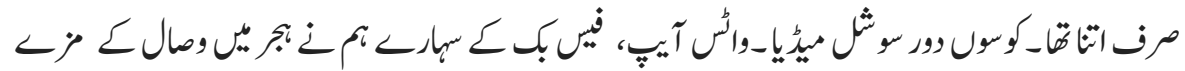

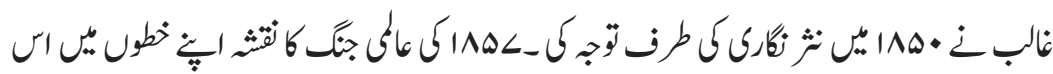

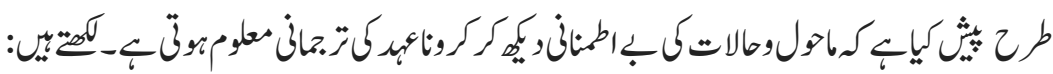

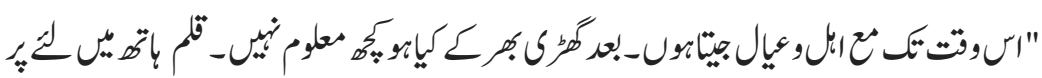

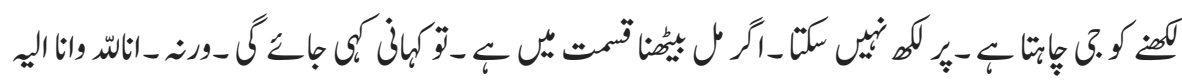
راجون-

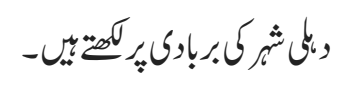

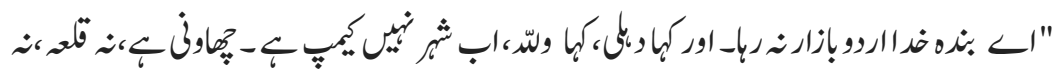

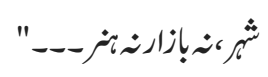

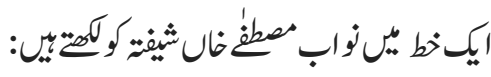




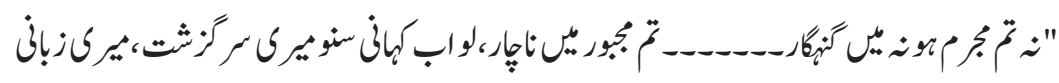

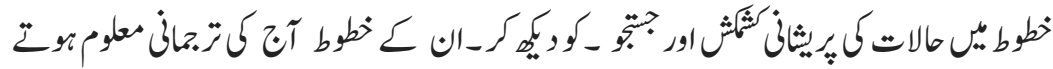

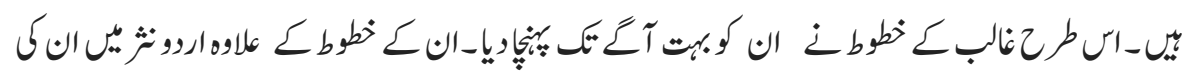

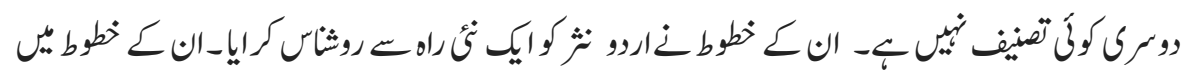

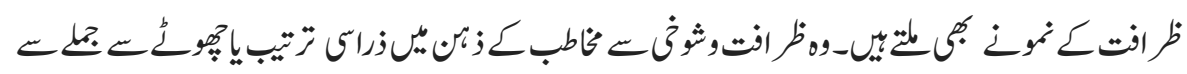

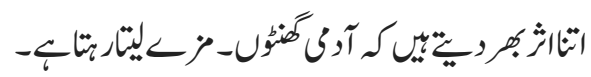

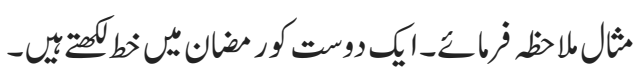

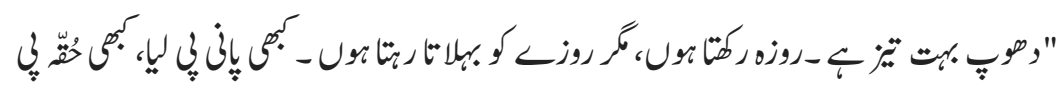

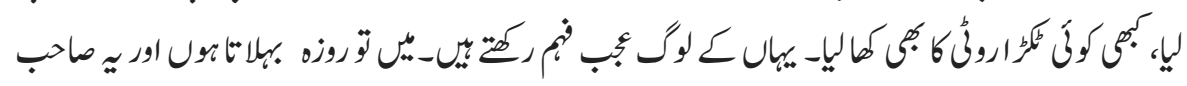

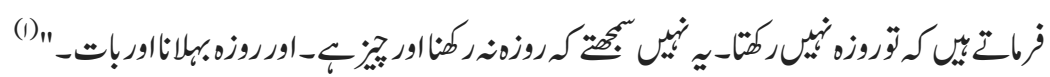

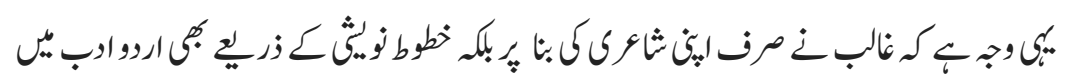

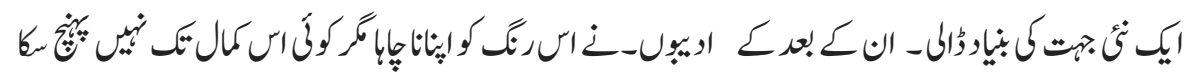

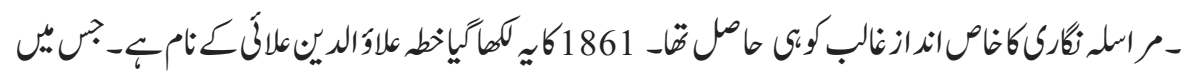

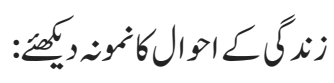

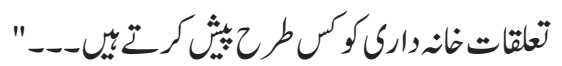

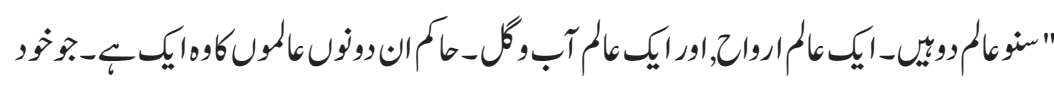

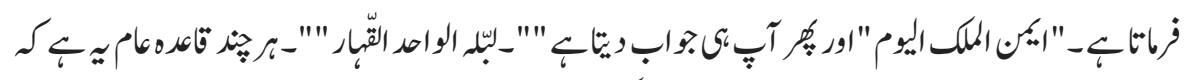

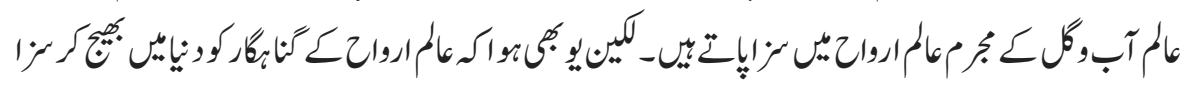
"

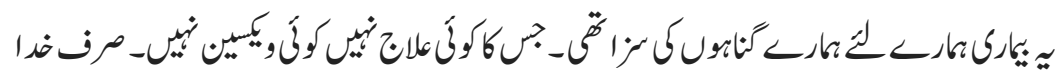

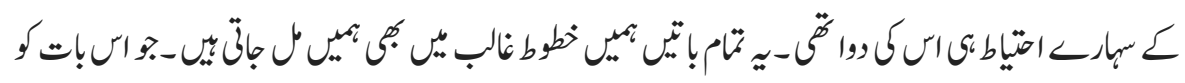

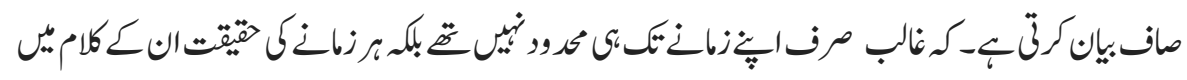




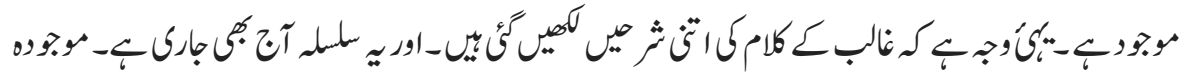

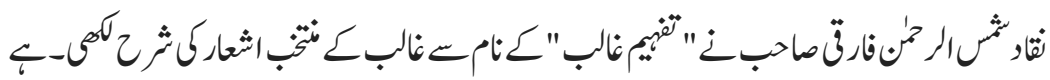

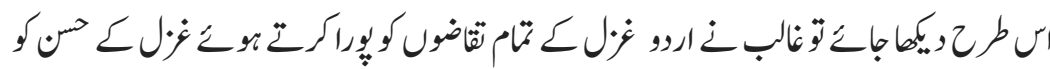

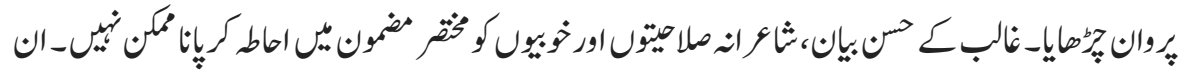

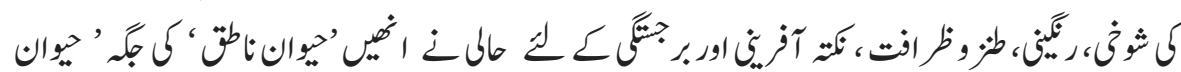

$$
\begin{aligned}
& \text { קريف كماب }
\end{aligned}
$$

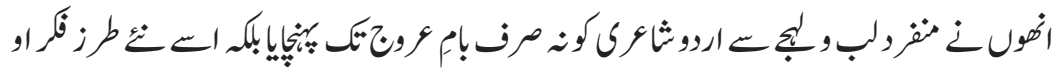

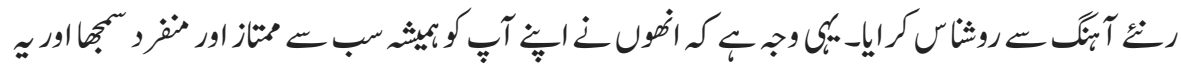

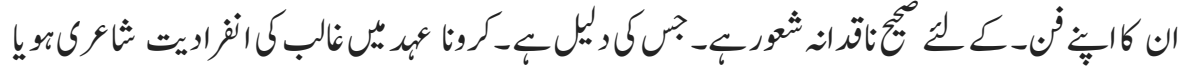

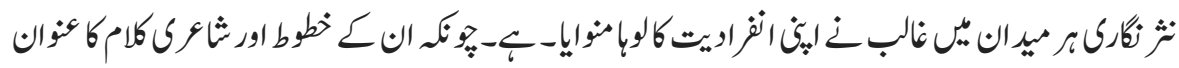

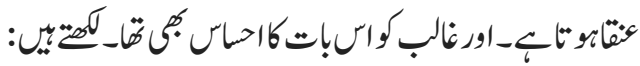

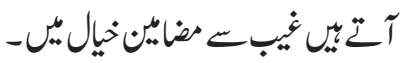

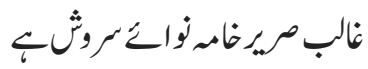

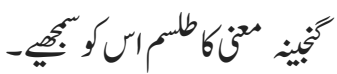

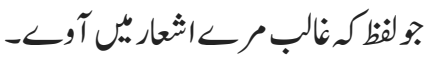

حوالم جإت

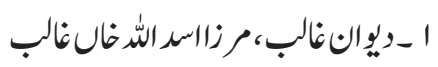

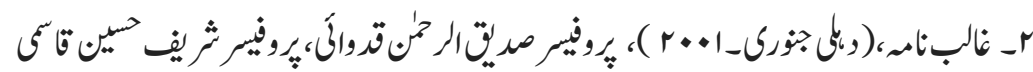

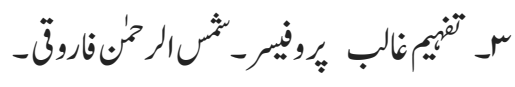

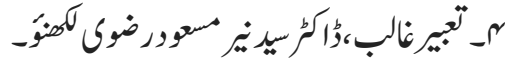

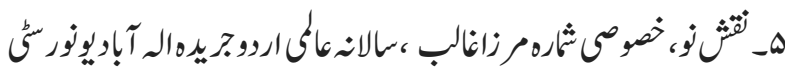

